\title{
The effect of age, gender, level of adiposity and diabetes duration on glycated hemoglobin reduction after anti-diabetic therapy in type-2 diabetic patients
}

\author{
Chinwe O. Ewenighi ${ }^{1}$, Uchechukwu Dimkpa $^{2^{*}}$, Babatunde I. Adejumo $^{3}$, Joel C. Onyeanusi ${ }^{1}$, \\ Isaac N. Nnatuanya ${ }^{4}$, Uzor Simon ${ }^{1}$, Linus U. M. Onoh ${ }^{5}$, Uchechukwu Ezeugwu ${ }^{6}$ \\ ${ }^{1}$ Medical Laboratory Science Department, Ebonyi State University, Abakaliki, Nigeria \\ ${ }^{2}$ Physiology Department, Nnewi Campus, Nnamdi Azikiwe University, Enugu, Nigeria; \\ *Corresponding Author: positivedoings@yahoo.com \\ ${ }^{3}$ Medical Laboratory Science Department, University of Benin, Benin City, Nigeria \\ ${ }^{4}$ Department of Chemical Pathology/Toxicology, Faculty of Medical Lab Sciences, Elele Campus, Madonna University, Okija, Nigeria \\ ${ }^{5}$ Department of Community Medicine, Enugu State University of Science and Technology, Enugu, Nigeria \\ ${ }^{6}$ Department of Physiotherapy, University of Nigeria Teaching Hospital, Enugu, Nigeria
}

Received 22 March 2012; revised 19 April 2012; accepted 11 May 2012

\section{ABSTRACT}

Background: It is established that glycemic control measures involving diet and oral medication reduce glycated hemoglobin concentration (HbA1c) in type-2 diabetic patients. Aim: We aimed to determine whether HbA1c reduction after diabetic treatment is affected by age, gender, level of adiposity and diabetes duration in type-2 diabetic patients. Methods: One hundred and four type-2 diabetic patients participated in a 20-week diabetic control therapy involving oral medication (metformin) and lifestyle intervention (diet). We compared the HbA1c reduction after treatment between the elderly and non-elderly; males and females; overweight/obese and nonoverweight/obese; and long-standing and newly diagnosed patients. Results: After the treatment, participants had mean HbA1c reduction of $1.1 \%$ $\pm 1.31 \%$ and weight loss of $2.46 \pm 1.79 \mathrm{~kg}$. Fortysix (44.2\%) of the patients had acceptable HbA1c level of $<6.5 \%$. Significantly greater HbA1c reduction was observed in non-elderly, non-overweight/obese and newly diagnosed patients compared to the elderly, overweight/obese and long-standing diabetic patients $(p<0.05$ or $p<$ 0.01 or $p<0.001$ ), respectively. HbA1c reduction did not indicate significant sex differences. Conclusion: The present findings suggest that treatment criteria for type-2 diabetes should account for the age, level of adiposity and diabetes duration of the patient in order to make optimal therapeutic decisions for the treatment of diabetes mellitus in adults.

Keywords: Glycated Hemoglobin; Age; Gender; Adiposity; Metformin; Diet

\section{INTRODUCTION}

Glycemic control measures are usually targeted toward reducing plasma glucose concentration. Such glycemic control measures are critical because, hyperglycaemia is associated with increased risk of micro-vascular complications, sensory neuropathy, myo-cardial infarction and stroke in patients with type-2 diabetes [1-4]. Maintaining glycaemic levels as close to the non-diabetic range as possible, has been demonstrated to have a powerful beneficial impact in reducing complications in type- 2 diabetes [5].

A previous study [6] has shown diabetes control therapy involving oral medication and lifestyle intervention (diet), to be an effective measure in achieving HbA1c reduction and weight loss in patients with type-2 diabetes. However, to the best of our knowledge, no previous study has demonstrated the effect of age, sex, level of adiposity or duration of diabetes on $\mathrm{HbAlc}$ reduction of type-2 diabetic patients after treatment. We believe that knowledge of these facts may improve the process of making optimal therapeutic decisions for the treatment of type-2 diabetes mellitus in adults. The present study therefore aimed at evaluating the effect of combination of oral medication (metformin) and life-style intervenetion (diet) on hyperglycemia and how this effect is dif- 
ferentiated between age groups, genders, level of adiposity and diabetes durations in those with type- 2 diabetes.

\section{METHODS}

\subsection{Subjects}

One hundred and twenty-seven type- 2 diabetic patients who met the inclusion criteria were recruited for the study. Of this population, 67 were recruited from students and staff of Igbinedion University, Okada, Edo state, Nigeria and had no history of diabetes prior to the study; 60 were patients who were already attending the diabetic clinic of the Igbinedion University Teaching Hospital prior to the study. The diagnosis of type-2 diabetes was based on medical history and the finding of a glycated hemoglobin value $\geq 6.5 \%$. A standard questionnaire on medical history was administered to the subjects to determine those eligible for the study. Those included in the study were 18 years of age or older; physically able to attend the clinic; either not taking diabetic medications or has been taking any other oral diabetic medication except metformin. Exclusion criteria included, those with a history of unstable cardiovascular and peripheral disease; those with chronic illnesses; those with recent blood loss or donated blood recently; those who have hemolytic anemia; and those using medications known to affect glucose metabolism. Blood samples were aseptically collected into floride oxalate and EDTA bottles for glycated hemoglobin measurement. For the purpose of this study, patients were grouped as elderly (age $\geq 60 \mathrm{yrs}$ ) or non-elderly (age $<60 \mathrm{yrs}$ ); non-overweight/obese (BMI $<25 \mathrm{~kg} / \mathrm{m}^{2}$ ) or overweight/obese (BMI of $\geq 25 \mathrm{~kg} / \mathrm{m}^{2}$ ); and newly diagnosed diabetics (diabetes duration $<18$ months) or long-standing diabetics ( $\geq 18$ months diabetes duration). The ethics committee of the institution approved the study and all the subjects gave their written informed consent prior to the study.

\subsection{Diabetic Treatment}

Three weeks prior to the commencement of active diabetic treatment, each patient was placed on a placebo and instructed to maintain a hypocaloric/high fiber diet within this period. Patients were also educated about diet and glycemic control. At the end of the three weeks, each patient's glycated hemoglobin level was checked. Those who recorded an HbAlc level of $<6.5 \%(n=5)$ were excluded from the study and could not proceed to the active treatment phase.

One hundred and twenty two patients who had HbAlc level $>6.5 \%$ progressed to the active treatment phase of the study. The active diabetic treatment involved the combination of drug (metformin) and diet (hypocaloric/ high fiber diet) therapies and lasted for the duration of 20 weeks. During the first visit (week 0) of active treatment, the patient's body mass index was determined and the HbAlc level measured. Treatment was initiated with an oral diabetic medication of $500 \mathrm{mg}$ metformin, thrice daily (i.e. a total of $1500 \mathrm{mg}$ ) with breakfast, lunch and dinner. The pharmacist provided drug information, while a dietician reinforced the instructions on hypocaloric/ high fiber diet to be followed by the patients through out the period of the treatment. The $2^{\text {nd }}$ and $3^{\text {rd }}$ visits occurred after the second and fourth weeks and with the metformin dose increased to $2500 \mathrm{mg} /$ day by adding a second $500 \mathrm{mg}$ tablet to the dinner and breakfast meals respectively. After the 5th week, patients were asked to maintain the maximal dose of metformin $(2500 \mathrm{mg}$ per day) unless side effects (gastro-intestinal or hypoglycemia) dictated a reduction in the dose. Subsequent visits by the patients were at 4 weeks intervals until the end of the treatment period. During each of these visits, information about drug compliance by patients and adverse drug reactions were obtained, while the dietician reinforced the dietary instructions. At the end of the $20^{\text {th }}$ week, patient's body mass index was determined, the HbAlc concentration measured and drug compliance evaluated. Compliance to oral medication was defined as the number of doses actually taken divided by the number prescribed [7]. Data for those who could not achieve $\geq 80 \%$ compliance with the prescribed regimen were excluded from the study. Reduction in HbAlc levels was the primary study endpoint and serves as the index of response to glycemic control therapy.

\subsection{Glycated Hemoglobin Estimation}

We analyzed glycated hemoglobin using ion exchange chromatographic method (DIALAB, Gieselhaft, Germany). Glycated hemoglobin samples were stored at $2^{\circ} \mathrm{C}$ $-8^{\circ} \mathrm{C}$ and the analysis done within one week. The following formula given by the manufacturer of the kit was used to obtain Diabetes Control Complications Trial referenced values: HbA1c (NGSP) $(\%)=0.86 \mathrm{HbA1c}-$ Dialab (\%) +0.24 .

\subsection{Anthropometric Measurement}

Subject's height was measured to the nearest $0.1 \mathrm{~cm}$, and weight to the nearest $0.1 \mathrm{~kg}$ in light clothing without shoes. BMI was then calculated as weight $(\mathrm{kg})$ divided by the square of the height $\left(\mathrm{m}^{2}\right)$.

\subsection{Statistical Analysis}

Descriptive data are presented as means and standard deviations (SD). Data analysis between the two groups was compared using the independent sample $t$-test. Linear regression was used to determine correlation 
between variables. All statistics were done using SPSS for Windows (Version 16.0). Statistical significance was set at $p<0.05$.

\section{RESULTS}

The demographic and baseline characteristic of subjects are as shown in Table 1. Of the 122 patients who participated in the active treatment, 104 (50 men, 54 women; mean age, $53.2 \pm 10.11$ yrs; BMI, $24.4 \pm 3.30$ $\mathrm{kg} / \mathrm{m}^{2}$; diabetes duration $2.9 \pm 3.94 \mathrm{yrs}$; and baseline HbAlc concentration, $8.6 \% \pm 1.85 \%$ ) were able to complete their clinical visits and achieved at least $80 \%$ adherence to their oral anti-diabetic prescription. Six of the patients could not complete their clinical visits; four could not complete the treatment due to adverse effects of drugs (gastro-intestinal); and eight could not achieve $80 \%$ compliance to drug prescription. The elderly had significantly higher BMI $(p<0.01)$ and diabetes duration $(p<0.05)$ compared to the non-elderly. There was no significant difference in baseline $\mathrm{HbAlc}$ levels between the elderly and non-elderly. No significant differences were observed between males and females with regard to age, BMI and baseline HbA1c levels. However, the males had significantly higher $(p<0.05)$ diabetes duration than the females. Overweight/obese diabetics had significantly higher age $(p<0.01)$, BMI $(p<0.001)$ and diabetes duration $(p<0.01)$ compared to the non-overweight/obese diabetics. Baseline HbAlc values did not differ between the overweight/obese and non-overweight/ obese groups. Long-standing diabetic patients had significantly higher age $(p<0.001)$, BMI $(p<0.05)$ and mean diabetes duration $(p<001)$ than those with newly diagnosed diabetes. However, no significant difference was found with regard to the baseline HbAlc levels between the two groups.

Characteristics of subjects at the end of the $20^{\text {th }}$ week of treatment are as shown in Table 2. The participants mean $\mathrm{HbA} 1 \mathrm{c}$ level was $7.5 \% \pm 1.72 \%$ after the 20 -week treatment, showing a reduction of $1.1 \% \pm 1.30 \%$ from the mean baseline value. Participants also showed a weight loss of $2.46 \pm 1.78 \mathrm{~kg}$ and BMI reduction of 0.94 $\pm 0.69 \mathrm{~kg} / \mathrm{m}^{2}$. Forty-six $(44.2 \%)$ of the patients had acceptable HbA1c level of $<6.5 \%$ after treatment. Mean weight loss and BMI reduction were significantly higher $(p<0.05)$ in non-elderly group compared to the elderly but statistically similar between genders, levels of adiposity and diabetes durations. Significantly greater HbA1c reductions were observed in non-elderly $(1.31 \%$; $p<0.01)$, non-overweight/obese $(1.47 \% ; p<0.001)$ and newly diagnosed diabetics $(1.96 ; p<0.05)$ compared to the elderly $(0.46 \%)$, overweight/obese $(0.45 \%)$ and longstanding $(0.91 \%)$ diabetic patients respectively, (Figure 1). There was no significant gender difference observed in $\mathrm{HbA} 1 \mathrm{c}$ reduction.

A linear regression analysis indicated significant negative correlations between $\mathrm{HbA} 1 \mathrm{c}$ reduction and age $(r=$ $-0.408 ; p<0.001)$, BMI $(r=-0.278 ; p<0.01)$ and diabetes duration $(r=-0.321 ; p<0.01)$ respectively. No significant correlation was observed between $\mathrm{HbAlc}$ reduction and $\operatorname{sex}(r=0.114 ; p=0.250)$.

\section{DISCUSSION}

The present study indicated a general reduction in glycated hemoglobin level and weight loss in all age, gender, adiposity and diabetes duration regimens, in type- 2 diabetic patients who underwent a 20 -week anti-diabetic treatment involving a combination of oral medication (metformin) and life-style intervention (diet). Our data strengthens previous evidence [6] that the addition of metformin to diet is an effective therapy in achieving $\mathrm{HbAlc}$ reduction and weight loss in patients with type- 2 diabetes.

Table 1. Demographic and baseline characteristics of subjects according to age, gender, adiposity level and diabetes duration.

\begin{tabular}{|c|c|c|c|c|c|}
\hline \multirow{2}{*}{ Participants } & $n(\%)$ & Age (yrs) & $\operatorname{BMI}\left(\mathrm{kg} / \mathrm{m}^{2}\right)$ & Diabetes Duration (yrs) & Baseline HbA1c (\%) \\
\hline & $104(100)$ & $53.2 \pm 10.11$ & $24.4 \pm 3.30$ & $2.9 \pm 3.94$ & $8.6 \pm 1.85$ \\
\hline \multicolumn{6}{|l|}{ Age Group } \\
\hline Non-elderly & $78(75)$ & $48.8 \pm 6.85$ & $23.9 \pm 3.27$ & $2.4 \pm 3.61$ & $8.6 \pm 1.89$ \\
\hline Elderly & $26(25)$ & $66.5 \pm 5.80^{* * *}$ & $25.9 \pm 3.01^{* *}$ & $4.6 \pm 4.49^{*}$ & $8.6 \pm 1.73$ \\
\hline \multicolumn{6}{|l|}{ Gender } \\
\hline Males & $50(48.1)$ & $53.6 \pm 11.68$ & $25.0 \pm 3.47$ & $3.8 \pm 4.74^{*}$ & $8.8 \pm 2.06$ \\
\hline Females & $54(51.9)$ & $52.8 \pm 8.51$ & $23.8 \pm 3.05$ & $2.1 \pm 2.80$ & $8.4 \pm 1.62$ \\
\hline \multicolumn{6}{|l|}{ Adiposity Level } \\
\hline Non-Overweight/Obese & $66(63.5)$ & $50.8 \pm 8.16$ & $22.2 \pm 1.49$ & $1.9 \pm 3.04$ & $8.7 \pm 0.37$ \\
\hline Overweight/Obese & $38(36.5)$ & $57.3 \pm 1186^{* *}$ & $28.2 \pm 1.56^{* * *}$ & $4.6 \pm 4.74^{* *}$ & $8.4 \pm 0.77$ \\
\hline \multicolumn{6}{|l|}{ Diabetes Duration } \\
\hline Newly-diagnosed & $60(57.7)$ & $49.9 \pm 9.39$ & $23.7 \pm 3.39$ & $1.4 \pm 3.16$ & $8.6 \pm 1.78$ \\
\hline Long-standing & $44(42.3)$ & $57.6 \pm 9.45^{* * *}$ & $25.3 \pm 2.99^{*}$ & $5.0 \pm 3.95^{* * *}$ & $8.6 \pm 1.99$ \\
\hline
\end{tabular}

Abbreviations: $\mathrm{BMI}=$ Body mass index HbAlc $=$ Glycated hemoglobin concentration. ${ }^{*} P<0.05 ;{ }^{* *} P<0.01 ;{ }^{* * *} P<0.001$. 
Table 2. Characteristics of subjects at the end of $20^{\text {th }}$ week of diabetes treatment according to age, gender, adiposity level and diabetes duration.

\begin{tabular}{|c|c|c|c|c|c|}
\hline \multirow{2}{*}{ Participants } & Weight (kg) & Weight Loss (kg) & Reduction in BMI $\left(\mathrm{kg} / \mathrm{m}^{2}\right)$ & HbA1c Level (\%) & $\begin{array}{c}\text { No. of Acceptable HbA1c } \\
\text { Level }(<6.5 \%)\end{array}$ \\
\hline & $62.2 \pm 8.59$ & $2.5 \pm 1.78$ & $0.9 \pm 0.69$ & $7.5 \pm 1.72$ & 46 \\
\hline \multicolumn{6}{|l|}{ Age Group } \\
\hline Non-elderly & $61.4 \pm 8.72$ & $2.7 \pm 1.72^{*}$ & $1.0 \pm 0.66^{*}$ & $7.3 \pm 1.64$ & 38 \\
\hline Elderly & $64.5 \pm 7.87$ & $1.8 \pm 1.83$ & $0.7 \pm 0.72$ & $8.1 \pm 1.85^{*}$ & 8 \\
\hline \multicolumn{6}{|l|}{ Gender } \\
\hline Males & $63.5 \pm 9.35$ & $2.6 \pm 2.02$ & $1.0 \pm 0.77$ & $7.9 \pm 1.91^{*}$ & 22 \\
\hline Females & $60.9 \pm 7.71$ & $2.4 \pm 1.55$ & $0.9 \pm 0.61$ & $7.1 \pm 1.44$ & 24 \\
\hline \multicolumn{6}{|l|}{ Adiposity Level } \\
\hline Non-Overweight/obese & $58.0 \pm 6.55$ & $2.4 \pm 1.52$ & $0.9 \pm 0.55$ & $7.2 \pm 1.76$ & 34 \\
\hline Overweight/obese & $69.3 \pm 6.86^{* * *}$ & $2.5 \pm 2.19$ & $1.0 \pm 0.89$ & $8.0 \pm 1.56^{*}$ & 12 \\
\hline \multicolumn{6}{|l|}{ Diabetes Duration } \\
\hline Newly-diagnosed & $62.3 \pm 8.83$ & $3.6 \pm 2.43$ & $1.3 \pm 0.85$ & $6.7 \pm 1.67$ & 32 \\
\hline Long-standing & $66.7 \pm 3.95$ & $2.5 \pm 2.20$ & $0.9 \pm 0.84$ & $6.7 \pm 1.36$ & 14 \\
\hline
\end{tabular}

Abbreviations: $\mathrm{BMI}=$ Body mass index; $\mathrm{HbAlc}=$ Glycated hemoglobin concentration. $P<0.05,{ }^{* * *} P<0.001$.

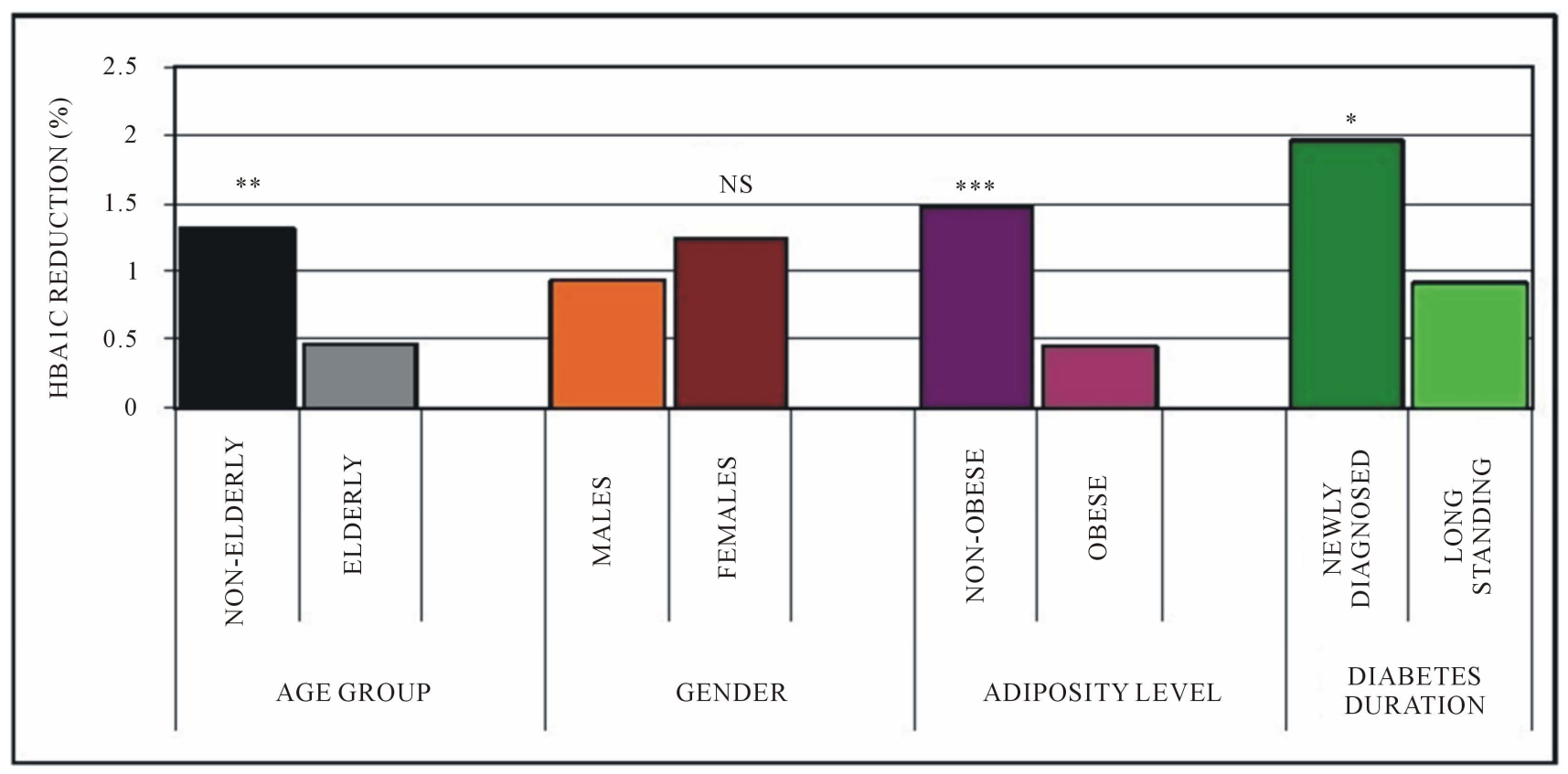

Figure 1. Glycated hemoglobin $(\mathrm{HbA} 1 \mathrm{c})$ reduction after treatment according to age, gender, adiposity level and diabetes duration. ${ }^{*} P$ $<0.05 ;{ }^{* *} \mathrm{P}<0.001$; NS $=$ not significant.

Our findings further indicated that older patients had lower HbAlc reduction compared to the younger ones. It has been reported that elevated basal hepatic glucose output is the primary factor responsible for increased fasting plasma glucose concentrations in patients with non-insulin dependent diabetes mellitus [8] and the effect of metformin is mediated through the inhibition of hepatic glucose production [6]. Aging has been associated with defects in glucose metabolism in both healthy and diabetic adults $[9,10]$. A progressive decline in renal function and decrease in total liver volume occur with advanced age and may result in reduced capacity in drug metabolism and slower elimination of drugs that are partially or completely cleared by the kidneys, including metformin and other diabetes agents [11-13].

Obesity and the associated metabolic complications are increasingly recognized as independent risk factors for diminished response to therapy and more severe liver disease [14]. Several types of hepatic conditions such as non-alcoholic fatty liver disease and chronic infection with hepatitis $\mathrm{C}$ virus are worsened by the presence of obesity in patients $[15,16]$. These facts suggest that increase in adiposity level may contribute to poor hepatic function, hence poor glucose metabolism and attenuated 
effect of anti-diabetic medication in those who are overweight/obese. The present study indicated lower HbA1c reductions in overweight/obese compared to non-overweight/obese patients. In contrast, a previous study [17] on diabetic patients treated with metformin has demonstrated that the $\mathrm{HbA} 1 \mathrm{c}$ reduction in non-obese diabetic patients was similar to that in obese patients.

It is not known whether diabetes duration affects responses to glycemic control therapy. However, because the liver plays a crucial role in glucose metabolism, it is not surprising that diabetes mellitus is a complication of many chronic liver diseases. Studies have shown that the association between diabetes mellitus and liver diseases such as chronic hepatitis, fatty liver, liver failure, cirrhosis and hepatocellular carcinoma are positively correlated with diabetes duration $[18,19]$. The long duration-induced complications of diabetes may interfere with the capacity of the liver in effective metabolism and may explain the lower response to glycemic control therapy observed in patients who had long-standing diabetes compared to the newly diagnosed diabetics in this study.

Previous studies have reported that men and women differ in behavior and attitudes toward their diabetes. For example, it has been reported that women tend to regulate their diabetes through diet, but they exercise less than men [20], report more negative impacts of diabetes [21], use the health care system more often than men [22], more inclined to comply with regular follow-up and have a tendency to have a more adaptive attitude toward diabetes [23]. These literatures seem to suggest the tendency of improved response to glycemic control measures in women compared to men. In the present study, both genders indicated similar age, BMI and baseline HbA1c. Similarly, irrespective of sex, patients in this study were regular with their clinic visits, achieved acceptable levels of drug compliance and followed their diet instructions seriously. These factors may have contributed to the lack of significant gender difference observed in $\mathrm{HbA} 1 \mathrm{c}$ reduction in this study.

\section{CONCLUSION}

The present study indicated lower $\mathrm{HbAlc}$ reductions in the elderly, overweight/obese and long-standing diabetic patients compared to the non-elderly, non-overweight/obese and newly-diagnosed patients. These findings suggest lower responses to glycemic control therapy in elderly, overweight/obese and long-standing type-2 diabetic patients when compared to the non-elderly, nonoverweight/obese and newly diagnosed diabetic patients. We recommend that the choice of glycaemic goals for type- 2 diabetes and the treatment criteria used to achieve them should take into consideration, the age, level of adiposity and diabetes duration of the patient in order to make optimal therapeutic decisions for the treatment of diabetes mellitus in adults.

\section{ACKNOWLEDGEMENTS}

We wish to thank all the staff and management of Igbinedion University Teaching Hospital for their immense support during the study. The authors are also very grateful to all the students and staff of Igbinedion University, Okada, as well as the patients of the Igbinedion Teaching Hospital, who participated in this study.

\section{REFERENCES}

[1] Klein, R. (1995) Hyperglycemia and microvascular and macrovascular disease in diabetes. Diabetes Care, 18, 258-268. doi:10.2337/diacare.18.2.258

[2] Adler, A.I., Boyko, E.J., Ahroni, A.J., Stensel, V., Forsberg, R.C. and Smith, D.G. (1997) Risk factors for diabetic peripheral sensory neuropathy. Results of the Seattle prospective diabetic foot study. Diabetes Care, 20, 11621167. doi:10.2337/diacare.20.7.1162

[3] Kuusisto, J., Mykkänen, L., Pyörälä, K. and Laakso, M. (1994) NIDDM and its metabolic control predict coronary heart disease in elderly subjects. Diabetes, 43, 960967. doi:10.2337/diabetes.43.8.960

[4] Lehto, S., Ronnemaa, T., Pyörälä, K. and Laakso, M. (1996) Predictors of stroke in middle-aged patients with non-insulin-dependent diabetes. Stroke, 27, 63-68. doi:10.1161/01.STR.27.1.63

[5] UK Prospective Diabetes Study (UKPDS) Group. (1998) Effect of intensive blood glucose control with metformin on complication in overweight patients with type 2 diabetes (UKPDS 34). The Lancet, 352, 854-865. doi:10.1016/S0140-6736(98)07037-8

[6] DeFronzo, R.A. and Goodman, A.M. (1995) Efficacy of metformin in patients with non-insulin-dependent diabetes mellitus. The New England Journal of Medicine, 333, 541-549. doi:10.1056/NEJM199508313330902

[7] Lee, V.W.Y. and Leung, P.Y. (2003) Glycemic control and medication compliance in diabetic patients in a pharmacist-managed clinic in Hong Kong. American Journal of Health-System Pharmacy, 60, 24.

[8] DeFronzo, R.A., Bonadonna, R.C. and Ferrannini, E. (1992) Pathogenesis of NIDDM: A balanced overview. Diabetes Care, 15, 318-368. doi:10.2337/diacare.15.3.318

[9] Meneilly, G.S., Elahi, D, Minaker, K.L., Sclater, A.L. and Rowe, J.W. (1989) Impairment of noninsulin-mediated glucose disposal in the elderly. The Journal of Clinical Endocrinology and Metabolism, 68, 566-571. doi:10.1210/jcem-68-3-566

[10] Reaven, G.M. (1977) Does age affect glucose tolerance? Geriatrics, 32, 51-54.

[11] Odegard, P.S., Setter, S.M. and Neumiller, J.J. (2007) Considerations for the pharmacological treatment of diabetes in older adults. Diabetes Spectrum, 20, 239-247. doi:10.2337/diaspect.20.4.239 
[12] Mangoni, A.A. and Jackson, H.D. (2003) Age-related changes in pharmacokinetics and pharmacodynamics: Basic principles and practical applications. British Journal of Clinical Pharmacology, 57, 6-14. doi:10.1046/j.1365-2125.2003.02007.x

[13] McLean, A.J. and LeCouteur, D.G. (2004) Aging biology and geriatrics clinical pharmacology. Pharmaceutical Reviews, 56, 163-184. doi:10.1124/pr.56.2.4

[14] Nobili, V., Kent, C.C. and Feldstein, A.E. (2011) Role of lifestyle changes in the management of chronic liver diseases. BMC Medicine, 9, 70. doi:10.1186/1741-7015-9-70

[15] Festi, D., Colecchia, A., Sacco, T., Bondi, M., Roda, E. and Marchesini, G. (2004) Hepatic steatosis in obese patients: Clinical aspects and prognostic significance. Obesity Reviews, 5, 27-42. doi:10.1111/j.1467-789X.2004.00126.x

[16] Hickman, I.J., Powell, E.E., Prins, J.B., et al. (2003) In overweight patients with chronic hepatitis $\mathrm{C}$, circulating insulin is associated with hepatic fibrosis: Implications for therapy. Journal of Hepatology, 39, 1042-1048. doi:10.1016/S0168-8278(03)00463-X

[17] Donnelly, L.A., Doney, A.S., Hattersley, A.T., Morris, A.D. and Pearson, E.R. (2006) The effect of obesity on glycaemic response to metformin or sulphonylureas in type 2 diabetes. Diabetes Medicine, 23, 128-133. doi:10.1111/j.1464-5491.2005.01755.x
[18] Yuan, J.M., Govindarajan, S., Arakawa, K. and Yu, M.C. (2004) Synergism of alcohol, diabetes, and viral hepatitis on the risk of hepatocellular carcinoma in blacks and whites in the US. Cancer, 101, 1009-1017.

[19] El-Serag, H.B., Tran, T. and Everhart, J.E. (2004) Diabetes increases the risk of chronic liver disease and hepatocellular carcinoma. Gastroenterology, 126, 460-468. doi:10.1053/i.gastro.2003.10.065

[20] Nothwehr, F. and Stump, T. (2000) Health-promoting behaviors among adults with type 2 diabetes: Findings from the Health and Retirement Study. Preventive Medicine, 30, 407-414. doi:10.1006/pmed.2000.0658

[21] Brooks, R.J. and Roxburgh, S. (1999) Gender differences in the effect of the subjective experience of diabetes and sense of control on distress. Health, 3, 399-420. doi: $10.1177 / 136345939900300404$

[22] Jonsson, P.M., Sterky, G., Gafvels, C. and Ostman, J. (2000) Gender equity in health care: The case of Swedish diabetes care. Health Care Women, 21, 413-431. doi:10.1080/07399330050082245

[23] Nielsen, A.B.S, Olivarius, N.F., Gannik, D., Hindsberger, C. and Hollnagel, H. (2006) Structured personal diabetes care in primary health care affects women's HbA1c. Diabetes Care, 29, 963-969. doi:10.2337/dc05-1807 